\title{
COMPARISON OF SEVOFLURANE AND PROPOFOL FOR INSERTION OF LARYNGEAL MASK AIRWAY IN ADULTS
}

\author{
Mamta Kumari1, Suvidha Sood², Gaurav Dhir ${ }^{3}$
}

${ }_{1}^{1}$ Assistant Professor, Department of Anaesthesiology, ESIC Medical College and Hospital, Faridabad, Haryana, India.

${ }^{2}$ Director Professor and HOD, Department of Anaesthesiology, ESIC Medical College and Hospital, Faridabad, Haryana, India.

3 Senior Resident, Department of Anaesthesiology, ESIC Medical College and Hospital, Faridabad, Haryana, India.

\section{ABSTRACT}

\section{BACKGROUND}

Satisfactory insertion of LMA after induction of anaesthesia [commencement of giving drugs either intravenous (IV) or inhalational to loss of eyelash reflex] requires sufficient depth of anaesthesia.

The aim of this randomised study was to compare the conditions for Laryngeal Mask Airway insertion following induction of anaesthesia with inhalation of Sevoflurane or intravenous induction with Propofol.

\section{MATERIALS AND METHODS}

The non-randomised controlled trial study was conducted with a sample size of 50 adults, ASA class I/II, aged between 18 - 60 years, scheduled for elective surgery after obtaining an informed written consent from the patients.

\section{RESULTS}

The results of our study showed that sevoflurane is associated with good haemodynamic stability, but quality of anaesthesia provided with propofol is superior with a statistically significant $\mathrm{p}$ value $<0.5$.

\section{CONCLUSION}

In our study, even though sevoflurane is associated with good haemodynamic stability, quality of anaesthesia provided with propofol is superior.

\section{KEY WORDS}

Adults, LMA, Sevoflurane, Propofol, Sample Size.

HOW TO CITE THIS ARTICLE: Kumari M, Sood S, Dhir G. Comparison of sevoflurane and propofol for insertion of laryngeal mask airway in adults. J. Evolution Med. Dent. Sci. 2018;7(41):4424-4428, DOI: 10.14260/jemds/2018/988

\section{BACKGROUND}

In anaesthesia Laryngeal Mask Airway (LMA) has gained widespread acceptance, as it provides an effective bridge between face mask and endotracheal tube, thereby providing effective (Spontaneous or Controlled) ventilation. ${ }^{1}$ It is a simple, well tolerated, safe, reusable and cost-effective device for airway management in both paediatric and adult patients. ${ }^{2,3}$ It minimises stress response and airway resistance. ${ }^{4}$

Satisfactory insertion of LMA after induction of anaesthesia [Commencement of giving drugs either intravenous (IV) or inhalational to loss of eyelash reflex] requires sufficient depth of anaesthesia.

Various studies have been carried out to find the ideal induction agent for LMA insertion.5,6 Sevoflurane is a recently introduced halogenated volatile anaesthetic agent. It is an attractive alternative to the currently available anaesthetics and has replaced halothane for inhaled anaesthetic induction in both paediatric and adult patients. ${ }^{7}$ Its low blood gas solubility, non-pungent odour and lack of irritation to the

'Financial or Other Competing Interest': None.

Submission 13-09-2018, Peer Review 25-09-2018,

Acceptance 27-09-2018, Published 08-10-2018.

Corresponding Author:

Dr. Gaurav Dhir,

House Number 809,

Sector 31, Faridabad-121003,

Haryana, India.

E-mail: gauravdhir2003@gmail.com

DOI: $10.14260 /$ jemds $/ 2018 / 988$

\section{(c) $(1)(5)$}

airway passage makes it a very useful anaesthetic for rapid induction and recovery from anaesthesia. ${ }^{8,9}$ Ability to induce and maintain anaesthesia with one drug, better conditions for LMA insertion, an ability to induce anaesthesia without IV access, thereby facilitating patient turnover in busy ambulatory settings are other advantages.9,10 It has disadvantages such as more frequent incidence of postoperative nausea and vomiting, agitation and increased pollution of the operating room with anaesthetics when compared with IV propofol.11 Propofol has replaced IV sodium thiopental and is the currently used IV agent of choice for induction and maintenance in outpatient, short surgical procedures because of its favourable recovery profile and low incidence of side effects like pain on injection and greater respiratory depression.12,13 Outcome assessment cannot be blinded as one drug is given IV and the other is inhaled.

Several studies have shown that induction of anaesthesia after inhalation of Sevoflurane is comparable with IV Propofol. The aim of this randomised study was to compare the conditions for Laryngeal Mask Airway insertion following induction of anaesthesia with inhalation of Sevoflurane or intravenous induction with Propofol.

\section{MATERIALS AND METHODS}

This non-randomised controlled trial study after informed consent, fifty ASA Grade I or II patients, between 18 and 60 years of age, undergoing general anaesthesia for elective surgery were enrolled in the study. Patients were excluded if they were predicted to have a difficult airway (Mallampati Grade III or IV), had a history of GI reflux, were receiving antiepileptic medication, had a history of cardiovascular, renal, 
hypertensive disease, pregnancy or known allergy to any anaesthetic. All the patients were fasting for at least 6 hours and the nil per oral (NPO) status was confirmed before the induction of anaesthesia. Every patient received tablet ranitidine $150 \mathrm{mg}$ and tablet ondansetron $4 \mathrm{mg}$ as premedication. Monitoring consisted of ECG, non-invasive blood pressure, $\mathrm{SpO} 2$ and ETCO2. Intravenous access was established, and the slow infusion of crystalloids commenced. Patients were randomised into one of the two groups- Group P: Propofol and Group S: Sevoflurane) of twenty-five each for induction of anaesthesia. Both groups received IV Fentanyl $(1.5-2 \mathrm{mcg} / \mathrm{kg}$ ) before induction of anaesthesia.

\section{Objectives}

1. To compare the induction with sevoflurane and propofol for LMA insertion.

2. To assess the quality of jaw relaxation between them for LMA insertion.

3. To compare the haemodynamic responses with both agents.

\section{Allocation of Groups}

All eligible consenting persons were included in the study and randomly allocated on the basis of a randomisation list in the study arm.

The non-randomised controlled trial study was of patients who were adults, ASA class I/II, aged between 18 60 years, scheduled for elective surgery attending the outpatient department. A total of 50 patients of patients who were adults, ASA class I/II were taken. Sample size was taken for convenience.

Prior to the induction of anaesthesia, patients in both groups had a face mask placed over their face and were breathing spontaneously. Group $\mathrm{P}$ received intravenous Propofol ( $2 \mathrm{mg} / \mathrm{kg}$ body weight) with $100 \%$ oxygen via the face mask. In Group S, the Magill's circuit was primed with Sevoflurane 8\% in 100\% 02 (Flow Rate 8 litres min-1) for 30 seconds. Each patient was asked to exhale maximally, and the primed circuit was then connected to the face mask. They were asked to take vital capacity breaths. Loss of eyelash reflex was considered as the end point of induction in both groups. Immediately, after loss of eye lash reflex, Laryngeal Mask Airway insertion was attempted by an experienced anaesthesiologist. The time for induction, i.e. the time (in secs.) taken from induction of anaesthesia to the loss of eye lash reflex and the time for Laryngeal Mask Airway insertion i.e. the time (in secs.) taken from loss of eye lash reflex to successful Laryngeal Mask Airway insertion were recorded in both the groups.

\begin{tabular}{|c|c|c|c|}
\hline $\begin{array}{c}\text { Introduction of the LMA } \\
\text { Jaw relaxation } \\
\text { ease of Insertion }\end{array}$ & $\begin{array}{c}\mathbf{3} \\
\text { Full } \\
\text { Easy }\end{array}$ & $\begin{array}{c}\mathbf{2} \\
\text { Partial } \\
\text { Difficult }\end{array}$ & $\begin{array}{c}\mathbf{1} \\
\text { Difficult } \\
\text { Impossible }\end{array}$ \\
\hline Patient's Response & 3 & 2 & 1 \\
Coughing & Nil & Transient & Persistent \\
Biting & Nil & Transient & Persistent \\
Gagging & Nil & Transient & Persistent \\
Laryngospasm & Nil & Partial & Total \\
\hline
\end{tabular}

Table 1. Grading of conditions for Laryngeal Mask Airway Insertion were Noted

Haemodynamic parameters (Systolic Blood Pressure, Diastolic Blood Pressure, Mean Arterial Pressure and Heart Rate) were recorded at baseline, at induction, at one, two and five minutes after induction. Statistical analysis was performed using student's unpaired t-test for demographic data and haemodynamic changes. Chi-square test incorporating Fisher's exact test and the Mann-Whitney test were used for the variables of induction and quality of Laryngeal Mask Airway insertion. $\mathrm{P}<0.05$ was taken as statistically significant.

\section{RESULTS}

There was no significant difference between the groups with respect to age, weight and ASA grade distribution. The mean age in Group P was $31.16 \pm 11.09$ (SD) and in Group S it was $37.68 \pm 11.89$ (SD). The mean weight in Group $\mathrm{P}$ was $55.7 \pm 7.89$ (SD) and in Group S it was $54.6 \pm 6.10$ (SD) Induction was more rapid with IV Propofol. The mean time (in seconds) for induction in Group P was $57.40 \pm 15.01$ (SD) and in Group S it was $65.40 \pm 9.67$ (SD) seconds $(\mathrm{p}=0.03)$. The difference in the meantime to Laryngeal Mask Airway insertion between the groups was found out to be statistically highly significant. The mean time (in seconds) for Laryngeal Mask Airway insertion in Group P was $100.80 \pm 14.48$ (SD) and in Group S it was $122 \pm 15.61$ (SD) seconds ( $<<0.001$ ), sevoflurane had taken longer time for induction and LMA insertion. Verbal contact, eye lash reflex, jaw relaxation and LMA insertion were lost earlier with propofol (Figure 1, Table 2). Two patients each in either group required a second attempt for insertion of Laryngeal Mask Airway, in the remaining 23 patients each in both groups Laryngeal Mask Airway was placed successfully at the first attempt itself. Conditions for Laryngeal Mask Airway insertion were noted. Excellent conditions were obtained in a significantly greater number of patients in Group P $(\mathrm{p}=0.0018)$ (Figure 2). Analysis of the total scores for conditions for Laryngeal Mask Airway insertion indicated that conditions for Laryngeal Mask Airway insertion were superior in Group P. The mean score in Group P was $17.8 \pm 0.41$ and $17.2 \pm 0.71$ in Group S ( $p=0.004$, Mann-Whitney 'U' test).

\begin{tabular}{|c|c|c|c|c|c|c|c|}
\hline & \multicolumn{3}{|c|}{ Propofol } & \multicolumn{3}{c|}{ Sevoflurane } & P value \\
\cline { 2 - 8 } & $\mathbf{N}$ & Mean & SD & N & Mean & SD & \\
\hline $\begin{array}{c}\text { Loss of verbal } \\
\text { eye contact }\end{array}$ & 25 & 57.40 & 15.01 & 25 & 65.40 & 9.67 & .030 \\
\hline Loss of eyelash reflex & 25 & 73.00 & 13.92 & 25 & 81.20 & 9.39 & .018 \\
\hline Jaw relaxation & 25 & 89.20 & 15.52 & 25 & 103.20 & 12.07 & 0.001 \\
\hline LMA insertion & 25 & 100.80 & 14.48 & 25 & 122.00 & 15.61 & 0.0001 \\
\hline \multicolumn{7}{|c|}{ Table 2 } \\
\hline
\end{tabular}



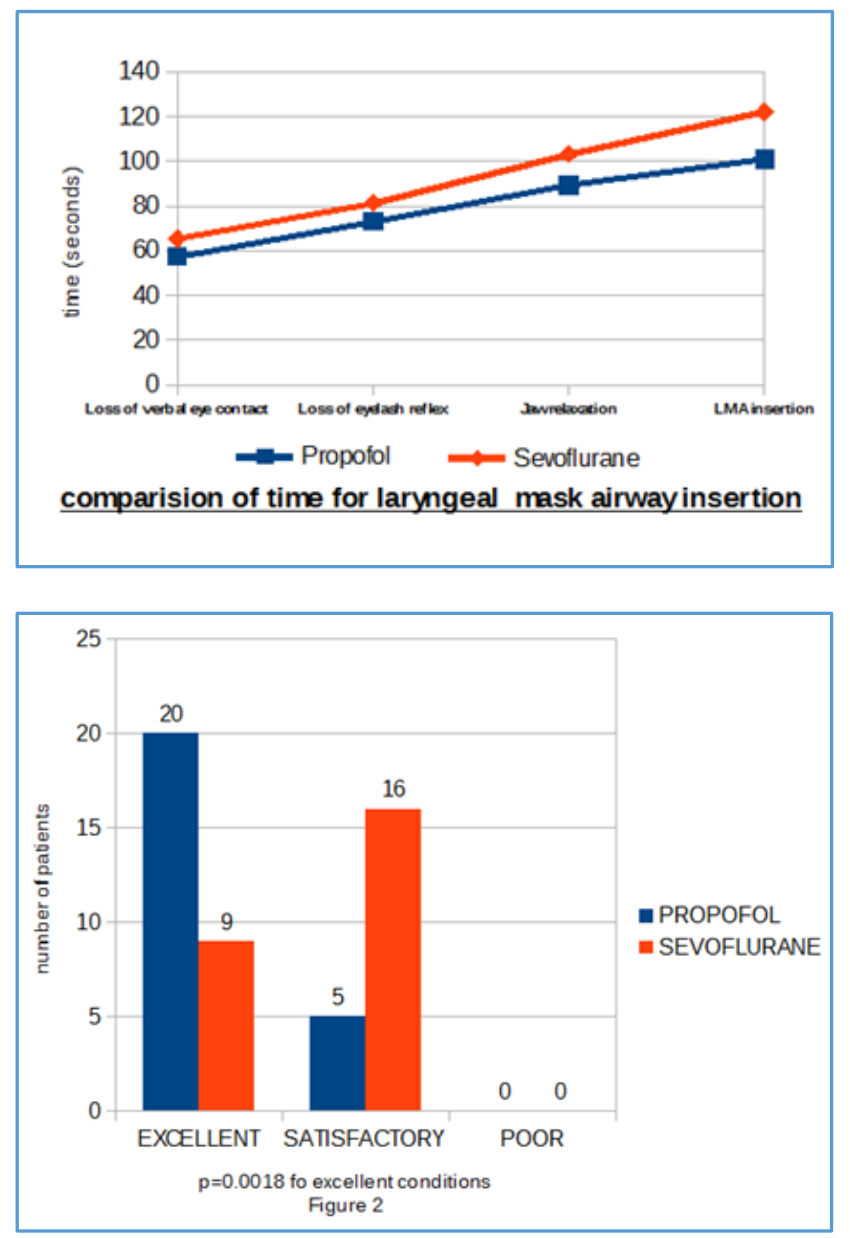

Analysis of the individual scores for criteria for Laryngeal Mask Airway insertion and the patient's response indicated that scores for jaw opening in Group $\mathrm{P}$ were significantly better than Group S ( $p=0.0253)$ (Table 3).

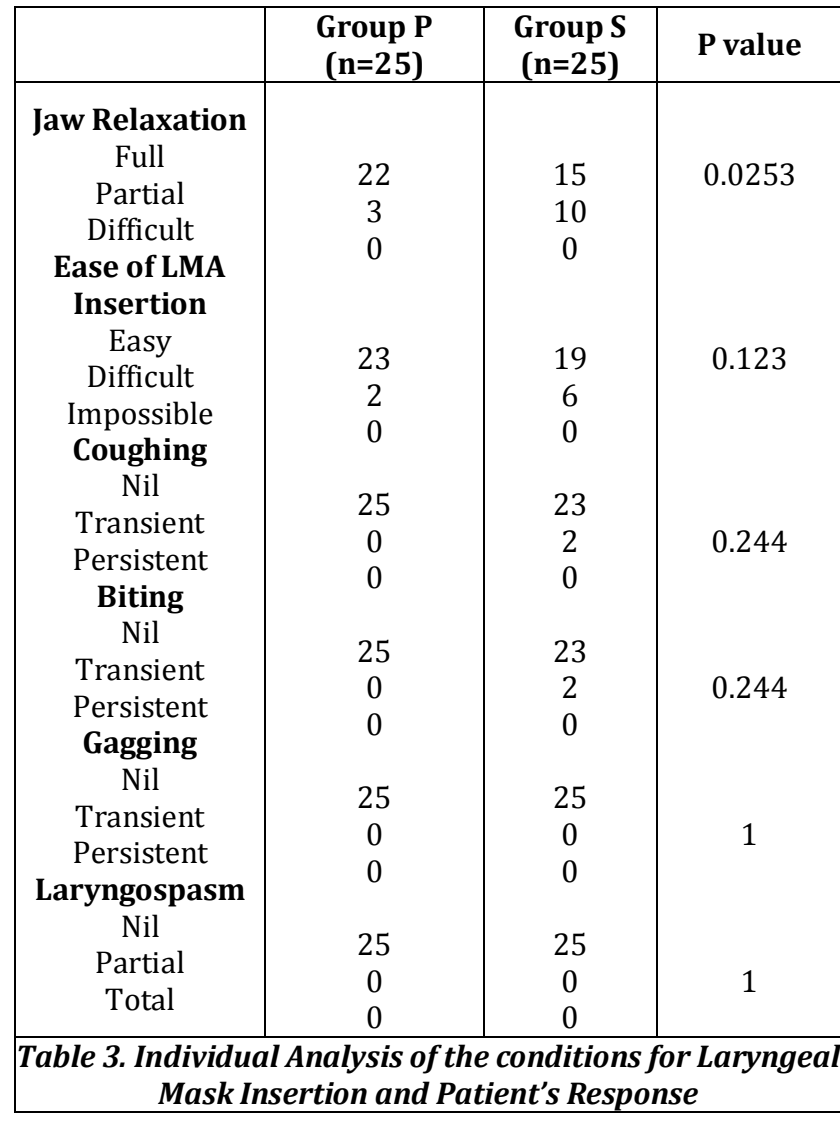

Both the groups exhibited stable haemodynamic profiles. Comparison of the various haemodynamic parameters (Systolic Blood Pressure, Diastolic Blood Pressure, Mean Arterial Pressure, Heart Rate) between the two groups showed a statistically significant difference in Group P one minute after induction. No statistically significant difference was noted at two and five minutes after induction (Table 4).

\begin{tabular}{|c|c|c|c|c|c|}
\hline & \multicolumn{5}{|c|}{ Time (Minutes) } \\
\hline & Pre & Induction & 1 & 2 & 5 \\
\hline SBP & & & & & \\
\hline Group P & $124.72 \pm 8.66$ & $119.44 \pm 9.23$ & $111.52 \pm 9.10$ & $107.84 \pm 7.96$ & $103.04 \pm 9.14$ \\
\hline Group S & $128.88 \pm 8.15$ & $125.36 \pm 12.0$ & $118.36 \pm 5.70$ & $112.56 \pm 9.01$ & $104.44 \pm 11.4$ \\
\hline$P$ value & .087 & .057 & .021 & .055 & .635 \\
\hline DBP & & & & & \\
\hline Group P & $78.40 \pm 6.78$ & $76.56 \pm 6.67$ & $70.56 \pm 5.40$ & $69.44 \pm 4.34$ & $65.84 \pm 9.41$ \\
\hline Group S & $81.44 \pm 8.28$ & $80.48 \pm 8.82$ & $74.00 \pm 7.64$ & $71.12 \pm 7.64$ & $69.44 \pm 8.73$ \\
\hline $\begin{array}{l}\text { P value } \\
\text { MAP }\end{array}$ & 0.162 & 0.083 & 0.042 & 0.344 & 0.167 \\
\hline Group P & $93.84 \pm 6.64$ & $90.85 \pm 6.11$ & $84.21 \pm 5.49$ & $81.88+4.88$ & $78.24+8.18$ \\
\hline Group S & $97.25 \pm 7.11$ & $93.44 \pm 8.40$ & $88.79 \pm 7.38$ & $84.93 \pm 7.72$ & $82.41 \pm 7.22$ \\
\hline$P$ value & 0.086 & 0.062 & 0016 & 0101 & $\begin{array}{l}0.062 \\
0\end{array}$ \\
\hline \multicolumn{6}{|l|}{ Heart Rate } \\
\hline Group P & $84.00 \pm 8.22$ & $81.56 \pm 7.92$ & $78.60 \pm 8.56$ & $77.28 \pm 8.99$ & $76.56 \pm 10.02$ \\
\hline Group S & $84.96 \pm 7.71$ & $84.48 \pm 8.20$ & $86.48 \pm 10.74$ & $82.68 \pm 11.76$ & $79.84 \pm 9.98$ \\
\hline$P$ value & 0.672 & 0.206 & 0.006 & 0.074 & 0.252 \\
\hline \multicolumn{6}{|c|}{ Table 4. Comparison of the Haemodynamic Parameters } \\
\hline
\end{tabular}

\section{DISCUSSION}

Satisfactory insertion of LMA after induction of anaesthesia requires sufficient depth of anaesthesia. ${ }^{14}$ Propofol is a common intravenous anaesthetic agent used for LMA insertion, because of its greater depressant effect on airway reflexes. Sevoflurane is suitable for inhalational induction technique even in high concentrations, because of its low blood gas solubility and minimal respiratory irritant effect. The vital capacity induction technique with sevoflurane was used to make the technique similar to that of intravenous bolus injection of propofol. ${ }^{15}$ Fentanyl was used as a coinduction agent, because of known synergistic effect of opioids with both sevoflurane and propofol. Propofol is a known induction agent for insertion of LMA with excellent 
jaw relaxation and allowed easy insertion of LMA. But is in no means ideal as it has been associated with several adverse effects including hypotension, apnoea and pain on injection. ${ }^{16}$ Sevoflurane has been used as an alternative to IV induction in adults, as it is associated with high patient acceptance and good haemodynamic stability. So in this study, we compared the quality and speed of LMA insertion in adult patients after sevoflurane VCB inhaled induction and propofol as intravenous induction of anaesthesia. 50 patients were randomly divided into two groups of 25 each. Group P (Propofol) and Group S (Sevoflurane). Patient's response to LMA insertion was noted and graded. Gagging, coughing, biting, laryngospasm, jaw relaxation and ease of LMA insertion were graded. In our study, mean time taken from induction to successful laryngeal mask insertion was significantly shorter with propofol compared with sevoflurane. With sevoflurane group the LMA insertion has taken $122 \pm 15.6$ seconds, while propofol has taken $100.8 \pm$ 14.48 seconds. Jaw relaxation has taken a longer time in sevoflurane group with $\mathrm{p}=0.001$, which is highly significant. In concurrence with our study, Priya et al ${ }^{11}$ in their study noted that propofol is known to depress laryngeal reflexes facilitating LMA insertion. They concluded that propofol is better than sevoflurane for LMA insertion using the loss of eyelash reflex as the end point of induction, probably due to better jaw relaxation. Similarly, Thwaites et al 10 in their study observed that induction with sevoflurane was significantly slower when compared with propofol (mean 84 (SD 24) sec vs. 57 (SD11) sec), but was associated with lower incidence of apnoea and shorter time to establish spontaneous ventilation. Induction of anaesthesia with sevoflurane was associated with advantage that mean arterial pressure was better maintained with sevoflurane as compared to propofol. The relative hypotension associated with propofol may be disadvantageous in elderly and coronary artery disease. In line with our study results, Thwaites et al in their study noted that induction of anaesthesia with propofol was associated with decrease of approximately $20 \mathrm{mmHg}$ in MAP, which occurred within 2 mins and persisted for at least 5 mins of anaesthesia. In contrast they noted that decrease with MAP with sevoflurane was only $10 \mathrm{mmHg}$. Gagging, coughing and biting was found in 2 patients in sevoflurane group, but was statistically not significant. In one patient in sevoflurane group both coughing and biting was noted. In a similar study conducted by Priya et al, ${ }^{11}$ features like coughing, gagging and patient movements did not reach statistical significance. Priya et al in their study noted that jaw relaxation with propofol was much better. With sevoflurane they noted that induction took longer time, because sevoflurane has less relaxation properties when compared to propofol. Philip et al12 in their study noted more airway related events (Cough, hiccough) in the sevoflurane group and more haemodynamic events in the propofol group, which is consistent with our study. The airway related incidents in our study was more in sevoflurane group when compared to propofol group, but is not of any statistical significance.

\section{Drawbacks in the Study}

1. Depth of anaesthesia between the two groups was not compared, as it was difficult to compare the depth of anaesthesia between inhaled and IV anaesthetics.

2. The anaesthetists who assessed induction side effects were not blinded to the induction technique.
3. Haemodynamic measurements were recorded once per minute during induction, perhaps episodes of hypotension or hypertension were missed within this assessment interval.

\section{CONCLUSION}

In our study, even though sevoflurane is associated with good haemodynamic stability, quality of anaesthesia provided by propofol is superior. Prolonged jaw relaxation with sevoflurane when compared to propofol may delay laryngeal mask airway insertion. None of the patients had trauma during insertion as noticed by absence of blood in LMA after removal in both groups. Patients who received propofol complained of pain while injection and patients who received sevoflurane complained of odour while mask was held. Thus, sevoflurane is an acceptable alternative to propofol for LMA insertion in adults.

\section{REFERENCES}

[1] Bogetz MS. Using the laryngeal mask airway to manage the difficult airway. Anaesthesiology Clin North America 2002;20(4):863-70.

[2] Krohner RG, Ramanathan S. Anatomy of airway in Benumof's airway management. 2nd edn. 2006: p. 1-19, 476-97, 1027-9.

[3] Brain AIJ. The laryngeal mask: a new concept in airway management. British Journal of Anaesthesia 1983;55(8):801-5

[4] Brimcombe JR. Laryngeal mask anaesthesia: principles and practice. $2^{\text {nd }}$ edn. Philadelphia, London: WB Saunders 2005: p. 35, 41, 115.

[5] Koppula R, Shenoy A. Comparison of sevoflurane with propofol for laryngeal mask airway insertion in adults. Anesth Clin Pharmacol 2005;21(3):271-4.

[6] Ti LK, Chow MY, Lee TL. Comparison of sevoflurane with propofol for laryngeal mask airway insertion in adults. Anesth Analog 1999;88(4):908-12.

[7] Smith CE, Lever JS, Sawkar S, et al. Sevoflurane - N2O versus propofol/ Isoflurane - N20 during elective surgery using the LMA in adults. J Clin Anesth 2000;12(5):392-6.

[8] Goodwin N, Campbell AE, Hall JE, et al. A comparison of $8 \%$ and $12 \%$ sevoflurane for inhalation induction in adults. Anesthesia 2004;59(1);15-9.

[9] Koh KF, Chen FG, Cheong KF, et al. Laryngeal mask insertion using thiopental and low dose atracurium: a comparison with propofol. Can J Anesth 1999;46(7):670-4.

[10] Thwaites A, Edmends S, Smith I. Inhalation induction with sevoflurane: a double - blind comparison with propofol. British Journal of Anesthesia 1997;78(4):356-61.

[11] Priya V, Divitia JV, Dasgupta D. Comparison of propofol versus sevoflurane for laryngeal mask airway insertion. Indian J Anesthesia 2002;46(1):31-4.

[12] Philip BK, Lombard LL, Roaf ER, et al. Comparison of vital capacity induction with sevoflurane to intravenous induction with propofol for adult ambulatory anesthesia. Anesth Analg 1999;89(3):6237. 
[13] Shao G, Zhan G. Comparison of propofol and sevoflurane for laryngeal mask airway patients in elderly patients. South Med J 2007;100(4):360-5.

[14] Ferson DZ, Brimcombe JR, Brain AIJ. The laryngeal mask airway. International Anesthesiology Clinics 1998;36(2).
[15] Baker CE, Smith I. Sevoflurane: a comparison between vital capacity and tidal breathing techniques for induction of anesthesia and laryngeal mask airway placement. Anesthesia 1999;54(9):841-4.

[16] Sebel PS, Lowdon JD. Propofol: a new intravenous anesthetic. Anesthesiology 1989;71(2):260-77. 